\title{
Identification of potential targets for an anticoagulant pectin
}

\author{
Aline Guimarães Santana a,b ${ }^{\mathrm{a}}$, Ana Helena Pereira Gracher ${ }^{\mathrm{b}}$, André Luis Rüdiger ${ }^{\mathrm{c}}$, Nilson Ivo Tonin Zanchin ${ }^{\mathrm{a}}$, \\ Paulo Costa Carvalho ${ }^{\text {a }}$, Thales Ricardo Cipriani ${ }^{\mathrm{b}}$, Tatiana de Arruda Campos Brasil de Souza ${ }^{\mathrm{a}, *}$ \\ a Instituto Carlos Chagas, FIOCRUZ/PR, Brazil \\ b Universidade Federal do Paraná (UFPR), Departamento de Bioquímica e Biologia Molecular, Brazil \\ c Universidade Federal do Paraná (UFPR), Departamento de Química, Brazil
}

\section{A R T I C L E I N F O}

\section{Article history:}

Received 2 February 2016

Received in revised form 25 May 2016

Accepted 9 June 2016

Available online $\mathrm{xxxx}$

\section{Keywords:}

Sulfated pectin

Anticoagulant

Molecular targets

\begin{abstract}
A B S T R A C T
Heparin is a sulfated polysaccharide of animal origin showing excellent anticoagulant properties. Although it strongly inhibits the coagulation cascade, its interaction with multiple sites results in several side effects. An ideal alternative compound should not only possess anticoagulant and antithrombotic activities, but also provide specific binding to components of the coagulation cascade to decrease side effects and facilitate the control of pharmacologic actions in patient's body. In this work, we performed a scan of potential targets for chemically sulfated pectin from Citrus sinensis (SCP) that shows an efficient anticoagulant activity by combining proteomics and molecular docking techniques. Defining the interaction partners of SCP is fundamental to evaluate if its pharmacological side effects can be as harmful as those from heparin. SCP interacts directly with heparin cofactor II, probably favoring its interaction with thrombin. SCP interaction with antithrombin depends likely on its association with thrombin or factor Xa. In addition to the interaction with factors related to homeostasis, SCP may also act on the renin-angiotensin and on the complement systems.

Biological significance: The knowledge of potential molecular targets of SCP provides clues to understand its mechanism of action in order to guide molecular changes in this compound to increase its specificity.
\end{abstract}

(c) 2016 Elsevier B.V. All rights reserved.

\section{Introduction}

Blood clotting is an essential and highly regulated physiological process [6]. Formation of fibrin clot in injured endothelium should prevent bleeding and allow injury repair without excessive formation of thrombus, which might cause ischemia [7]. Circulatory system diseases are associated to high mortality rate, with cardiovascular disorders in combination with thrombosis being the major causes of death [8]. When not resulting in death, they often cause some degree of disability, leading to serious consequences to patients and families, as well to unfavorable socio-economic effects [9]. The number of people affected by vascular hypercoagulable states has increased considerably worldwide, and in addition to genetic background, there are environmental and behavioral factors closely linked to this emergence [9].

Heparin is a highly sulfated linear polysaccharide of animal origin belonging to the family of glycosaminoglycan. It consists of disaccharide

\footnotetext{
* Corresponding author at: Tatiana de Arruda Campos Brasil de Souza, Instituto Carlos Chagas, ICC-FIOCRUZ-PR, Rua Prof. Algacyr Munhoz Mader, 3775, bloco C, 81350-010 Curitiba, PR, Brazil.

E-mail address: tatianabrasil@fiocruz.br (T. de Arruda Campos Brasil de Souza).
}

units of $\alpha$-D-glucosamine and uronic acid joined by $\alpha-1 \rightarrow 4$ glycosidic linkages [10]. Since its discovery, heparin is the most widely used drug in the pro-clotting disorders [11]. Heparin inhibits the coagulation cascade by facilitating the binding between thrombin and antithrombin (AT) or heparin cofactor II (HCII), acting as a template in the formation of the ternary complex, and also favoring the binding of AT to factor Xa [2]. A specific pentasaccharide sequence has been proposed to be responsible for binding to AT [2,3]. However, the interaction with HCII may not require a specific oligosaccharide sequence, being related only to the negatively charged sulfate groups [5].

Although widely used in medical treatment, heparin has many disadvantages, such as risk of contamination with pathogens, bleeding, thrombocytopenia, bruises, contact dermatitis, hives and necrosis of epithelium [12,13]. These side effects serve as motivation in the quest for alternative compounds to heparin, whereas other natural or chemically sulfated polysaccharides have shown promising results [14]. Sulfated polysaccharides such as glucans, fucans, galactans, ramnanan, arabinogalactan, xyloarabinogalactan affect homeostasis in different manners [1,14-17]. In general, the anticoagulant action of sulfated polysaccharides takes place by means of potentiation of the action of natural inhibitors of the clotting cascade, such as AT and HCII [18]. However, several studies have indicated that in many cases the inhibition may 
occur by other mechanisms, such as direct inhibition of proteases or interaction with other components of the coagulation cascade [18].

After chemical sulfation, numerous fungal and plant polysaccharides acquired the property of inhibiting the coagulation process [1,19-21]. This work aimed in scanning for plasma proteins capable of interacting and/or reacting with SCP, a chemically sulfated polysaccharide obtained from Citrus sinensis mesocarp, that has an anticoagulant effect [22]. To achieve this, we introduce a hybrid approach that combines mass spectrometry based proteomics and molecular docking. Our results describe several interacting partners to SCP and thus increasing current knowledge on how this molecule acts to inhibit the coagulation cascade. Ultimately, these interacting partners shed light on mechanism of action of chemically sulfated polysaccharides; setting the grounds to engineering compounds with improved selectivity and better prediction of effects on patients.

\section{Experimental procedure}

\subsection{Sulfation of citrus pectin}

Citrus pectin was extracted from Citrus sinensis mesocarp, purified and chemically sulfated as described in previous work, giving SCP [23, 22].

\subsection{Plasma extraction}

Peripheral human blood was obtained from volunteer donors (female, 20 years) and the plasma fraction was obtained by centrifugation of the blood cells directly in the collecting blood tubes containing sodium citrate at $3.2 \%$.

\subsection{Depletion of albumin from plasma}

Our albumin-depletion protocol consists in ethanol precipitation associated to $\mathrm{pH}$ changes at low temperatures. To achieve this, equal volumes of saline solution and plasma were mixed and had their $\mathrm{pH}$ adjusted to 4.8 using $0.1 \mathrm{M} \mathrm{HCl}$. The suspension was centrifuged at $10,621 \mathrm{~g}$ for $20 \mathrm{~min}$ at $15^{\circ} \mathrm{C}$. The pellet was discarded and the supernatant transferred to a fresh tube. The $\mathrm{pH}$ was adjusted to 7.0 with $0.1 \mathrm{M}$ $\mathrm{NaOH}$ followed by addition of $28 \%(\mathrm{v} / \mathrm{v})$ ice-cold absolute ethanol. After 20 min of incubation at $-20^{\circ} \mathrm{C}$, the sample was centrifuged at $10,621 \mathrm{~g}$ at $4{ }^{\circ} \mathrm{C}$ for $20 \mathrm{~min}$. The supernatant was discarded and the pellet was resuspended in $20 \mathrm{mM}$ of Tris buffer at $\mathrm{pH}$ 8.0. The resuspended samples were analyzed by SDS-PAGE on $13 \%$ polyacrylamide gel.

\subsection{Fractionation of blood proteins}

Following albumin depletion, the plasma aliquots were fractionated by size exclusion (SEC), anion exchange (AEX) and cation exchange (CEX) chromatography using Superdex 200 10/300 GL, Hitrap Q FF and Hitrap SP HP as stationary phases, respectively. $3.2 \%$ sodium citrate buffer $\mathrm{pH} 7.0$ was used as mobile phase in SEC. $20 \mathrm{mM}$ Tris buffer $\mathrm{pH} 8.0$ was used as binding buffer and the proteins were eluted with a linear gradient of $20 \mathrm{mM}$ Tris buffer $\mathrm{pH}$ 8.0, $1 \mathrm{M} \mathrm{NaCl}$ in ionic exchange chromatographies (IEX). Aliquots of each fraction were analyzed by electrophoresis on 13\% SDS-PAGE and the chromatographic fractions with similar protein profile were grouped and annotated as a subset.

\subsection{Differential scanning fluorimetry (DSF)}

The analysis of the interaction SCP with plasma proteins was performed by fluorescence-based thermal shift assays. The experiments were performed using different subsets of the plasma fractionation. The final concentrations were: $0.5 \mu \mathrm{g}$ to $2.5 \mu \mathrm{g}$ of total protein, $25 \mu \mathrm{g}$ of SCP and SYPRO orange. Three independent experiments were performed on a Real-Time PCR machine 7300 (Applied Biosystems). Each denaturation curve in the presence of SCP was compared to its counterpart in the absence of compound. GraphPad Prism 6 was used to determine the inflection points of the denaturation curves (Pi). The melting temperature variation $(\Delta \mathrm{Tm})$ was calculated using the equation: $\Delta \mathrm{Tm}=\mathrm{Pi}$ in the presence of SCP $-\mathrm{Pi}$ in the absence of SCP.

\subsection{LC-MS/MS acquisition}

The plasma proteins in the subsets that showed interaction with SCP in DSF were identified by mass spectrometry. For this analysis, proteins were reduced with DTT, alkylated with iodoacetamide and digested with trypsin overnight. The peptides were subjected to LC-MS/MS analysis using a Thermo Scientific Easy-nLC 1000 ultra-high performance liquid chromatography (UPLC) system coupled online to a LTQ-Orbitrap XL ETD mass spectrometer (Mass Spectrometry Facility - RPT02H PDTIS/Carlos Chagas Institute - Fiocruz Paraná), as follows. The peptide mixtures were loaded onto a column (75 mm i.d., $15 \mathrm{~cm}$ long) packed in house with a $3.2 \mu \mathrm{m}$ ReproSil-Pur C18-AQ resin (Dr. Maisch) with a flow of $500 \mathrm{~nL} / \mathrm{min}$ and subsequently eluted with a flow of $250 \mathrm{~nL} / \mathrm{min}$ from $5 \%$ to $40 \% \mathrm{ACN}$ in $0.5 \%$ formic acid and $0.5 \% \mathrm{DMSO}$, in a $120 \mathrm{~min}$ gradient. The mass spectrometer was set in data-dependent mode to automatically switch between MS and MS/MS acquisition. Survey full scan MS spectra (from $m / z 300$ to 2000) were acquired in the Orbitrap analyzer with resolution $\mathrm{R}=60,000$ at $\mathrm{m} / z 400$ (after accumulation to a target value of $1,000,000$ in the linear trap). The ten most intense ions were sequentially isolated and fragmented in the linear ion trap. Previous target ions selected for MS/MS were dynamically excluded for $90 \mathrm{~s}$. Total cycle time was approximately $3 \mathrm{~s}$. The general mass spectrometric conditions were: spray voltage, $2.4 \mathrm{kV}$; no sheath and auxiliary gas flow; ion transfer tube temperature $100{ }^{\circ} \mathrm{C}$; collision gas pressure, $1.3 \mathrm{mTorr}$; normalized energy collision energy using wide-band activation mode; $35 \%$ for MS/MS. Ion selection thresholds were: 250 counts for MS2. An activation $\mathrm{q}=0.25$ and activation time of $30 \mathrm{~ms}$ were applied in MS2 acquisitions.

\subsection{Peptide spectrum matching}

The reviewed proteome set of Homo sapiens, composed of 20,187 sequences, was downloaded from the UniProt consortium on July 4th, 2014. PatternLab 4.0 was used for generating a target-decoy database by grouping subset sequences, adding the sequences of 127 common mass spectrometry contaminants, and, for each sequence, including a reversed version of it. The final database used for PSM contained 105,551 sequences.

The Comet 2015 rev. 2 search engine [24], which is embedded into PatternLab for proteomics 4.0 [25], was used to compare experimental tandem mass spectra against those theoretically generated from our sequence database and select the most likely peptide sequence candidate for each spectrum. Briefly, the search was limited to fully peptide candidates; we imposed carbamidomethylation of cysteine and oxidation of methionine as fixed and variable modification, respectively. The search engine accepted peptide candidates within a 40-ppm tolerance from the measured precursor $m / z$ and used the XCorr as the primary search engine score.

PSM validity was assessed using the search engine processor (SEPro) [26], which is embedded in PatternLab. Briefly, identifications were grouped by charge state $(+2$ and $\geq+3)$ resulting in two distinct subgroups. For each result, the Comet XCorr, DeltaCN, DeltaPPM, and Peaks Matched values were used to generate a Bayesian discriminator. The identifications were sorted in non-decreasing order according to the discriminator score. A cutoff score was established to accept a false-discovery rate (FDR) of $1 \%$ at the peptide level based on the number of labeled decoys. This procedure was independently performed on each data subset, resulting in an FDR that was independent of charge state. Additionally, a minimum sequence length of six amino-acid residues was required. Results were post-processed to only accept peptide 
spectrum matches with less than 6 ppm from the global identification average and proteins with two or more identified peptides.

\subsection{Protein relative quantitation by normalized ion abundance factors}

In this work, we employed PatternLab's Normalized Ion Abundance Factors (NIAF) as a quantitation strategy. It is worth noting that NIAF is the equivalent do NSAF [27], but applied to Extracted Ion Chromatograms (XICs) as previously described in [28].

\subsection{From data to list of interacting candidates}

Independent DFS assessments were performed ranging total protein concentration of subsets presenting increase in thermal stability in order to estimate the threshold of total protein to detect Tm variation. The relative abundance of each protein was inferred according to its NIAF. Probable targets of SCP meet two requirements: 1) are in concentrations above $2 \mathrm{ng}$ in data presenting thermal shift and 2) below $2 \mathrm{ng}$ when no Tm variation was observed (Supplementary material Table S2). The 2 ng threshold is because, according to the manufacturer, only proteins above this concentration have their fluorescence emission detected.

\subsection{Assessment of complexes viability through molecular docking}

A 3D structure of one of SCP's pentasaccharide units was modeled using the $\mathrm{ACD} /$ ChemSketch software and using previously published data on its chemical composition [22]. The 3D model was optimized using the Avogadro program (v.1.1.1) with the Universal Force Field (UFF) method in auto optimization tool [29]. The 3D structures deposited in the Protein Data Bank (PDB) of the platelet factor IV (PDB ID 1F9Q), heparin cofactor II (PDB ID 1JMJ), Complement protease C1s (PDB ID 4J1Y), Prothrombin I (PDB ID 3NXP), Complement factor B (PDB ID 2OK5), Angiotensinogen (PDB ID 2WXW) and Complement protease C1r (PDB ID 1MD7) were used for molecular docking. A molecular dynamics simulation for each of the aforementioned proteins under the Amber force field was performed using Abalone (Copyright @ 2006 2015 Agile Molecule) with the temperature set to $350 \mathrm{~K}$ and a simulation time of 10,000 ps. Global molecular docking simulations were conducted using Autodock VINA [30] with 25 runs and 5 Å clustering RMSD. The viability of the complexes generated by MVD was verified using PEARLS (Energetic Program for Analysis of Receptor-Ligand System) [31] to assess the protein-ligand interaction energies.

\section{Results}

\subsection{Assessing the effectiveness of the albumin-depletion process}

The effectiveness of our albumin-depletion protocol was evaluated by generating an SDS-PAGE to follow up on each step of the albumin removal protocol. Our results show that albumin was efficiently depleted while minimally affecting other plasma proteins (Fig. 1A). Lanes 3 and 4 are results from the first step of our protocol that performs isoelectric precipitation from the supernatant at $\mathrm{pH}$ 4.8. Subsequently, ethanol
A

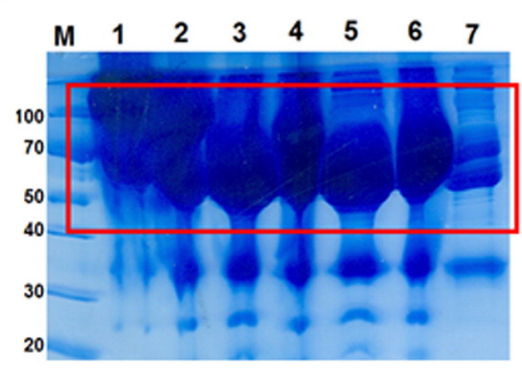

B

\begin{tabular}{c|c} 
SUBSETS & DTm \\
\hline pl1 & 3.3 \\
p12 & 1.4 \\
p14 & 7.39 \\
pl5 & 0.39
\end{tabular}

\section{C}

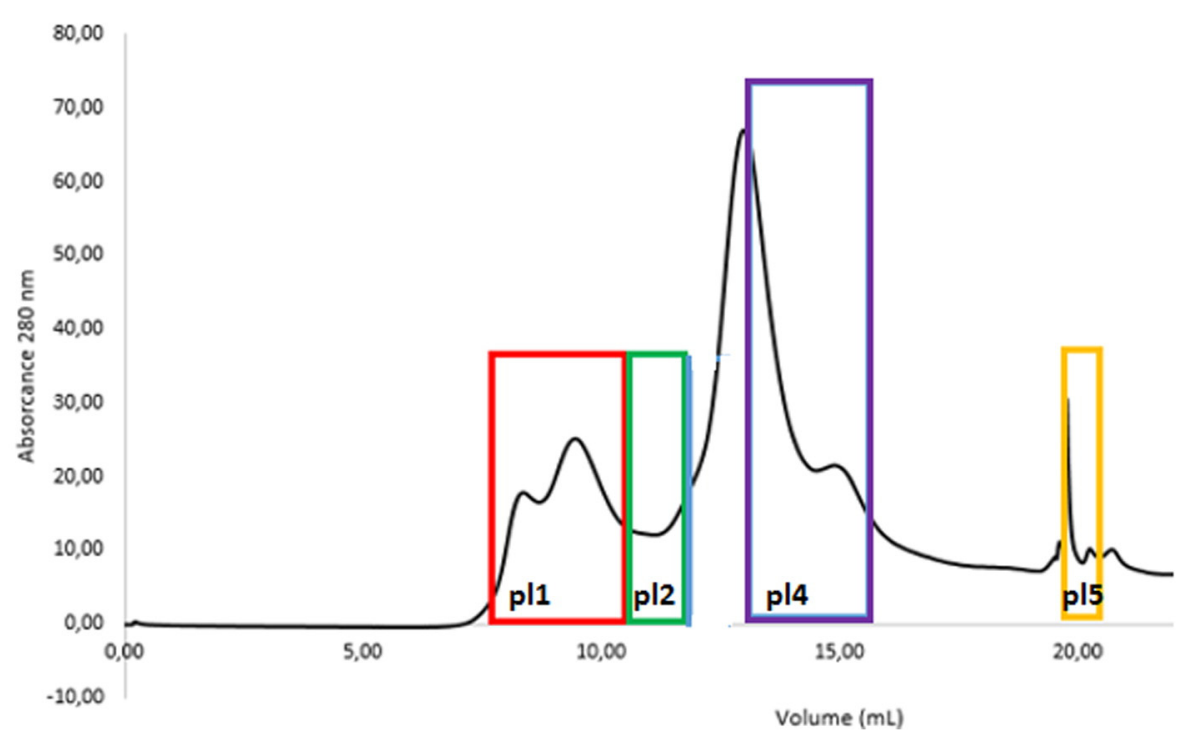

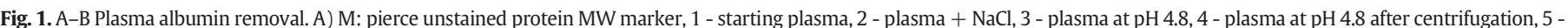

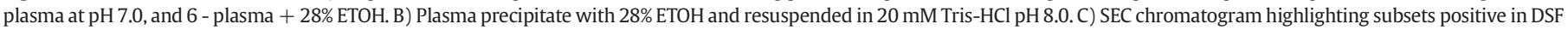

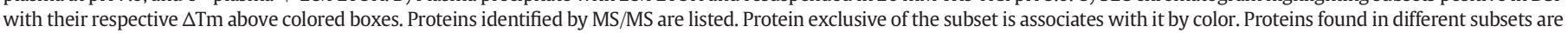
described in black. 
precipitation is performed; a visual assessment shows that a significant portion of the albumin is now depleted (Fig. 1A, lane 7). We note that neither acidic $\mathrm{pH}$ nor ethanol precipitation affect solubility of most plasma proteins as observed after resuspension of the ethanoic precipitate in $20 \mathrm{mM}$ Tris buffer $\mathrm{pH} 8.0$ (Fig. 1A, lane 7) and by proteomics indicating that mainly abundant plasma proteins are present in sample while significantly reducing the albumin abundance (Table S1).

In what followed, the albumin-depleted plasma was fractioned into 12 subsets (pl1, pl2, pl3, pl4, pl5, pl6, pl7, pl8, pl9, pl10, pl11, pl12). Each subset comprises fractions with same electrophoretic profile (Supplementary Figs. S1, S2 and S3).

\subsection{MS/MS identification of plasma proteins in the fractions the showed in- creased thermal stability}

The thermal stability of pl1-12 subsets was evaluated by DSF. Subsets pl1, pl2, pl4, and pl5 presented an increase in thermal stability with $\Delta \mathrm{Tm}$ of $3.3^{\circ} \mathrm{C}, 1.45{ }^{\circ} \mathrm{C}, 7.39^{\circ} \mathrm{C}$ and $0.39{ }^{\circ} \mathrm{C}$, respectively (Fig. 1C). No increase in Tm was observed in other subsets.

MS/MS enabled identification of hundreds of proteins in fractions pl1, pl2, pl4, and pl5 (Table S1) ultimately providing a list of SCP interaction candidates. A reduced list was obtained by cherry-picking candidates taking the following into account: 1) DSF results with different concentrations of $\mathrm{pl} 1, \mathrm{pl} 2, \mathrm{pl} 4$ and $\mathrm{pl} 5$ indicated the minimum sample concentration needed to fluorescence emission detection (Tables S2, S3). 2) NIAFs being used as surrogates for protein abundance percentages (Tables S2, S3). 3) The minimum concentration for a protein's fluorescence to be detected being of $2 \mathrm{ng}$ [32]. Following those steps, proteins with concentration below $2 \mathrm{ng}$ in experiments with no fluorescence emission signal and above it when fluorescence emission detect was assigned as probable partner of SCP (Table 1).

From this initial list, 12 proteins were excluded as potential partners of SCP as they were also presented in fractions without Tm alteration (Fig. 2A-B, Table 1). Among the remaining proteins, the association with coagulation pathway and robustness of the MS/MS identification (Table 1) were our decision factors to shortlisting a protein as a SCP interactor candidate. As a result, platelet factor IV, heparin cofactor, Complement protease C1s, Prothrombin I, Complement Factor B, angiotensinogen, complement protease $\mathrm{C} 1 \mathrm{r}$ comprise our final list of SCP interaction partner candidates (Fig. 2B) and further assessed by molecular docking approaches.

\subsection{In silico analysis of SCP putative binding partners}

As Heparin, SCP can interact with HCII with a total interaction energy of $-1.02 \mathrm{kcal} / \mathrm{mol}$ (Table 2, Fig. 3B) and with platelet factor 4 $(\Delta \mathrm{G}=-10.47 \mathrm{kcal} / \mathrm{mol}$, Table 2, Fig. 3A). The results of in silico analyses shows that, under physiological $\mathrm{pH}$ conditions, prothrombin by itself is unable to interact with SCP and therefore unable to prevent its conversion to thrombin with $3.01 \mathrm{kcal} / \mathrm{mol}$ of energy is required for this to happen (Fig. 3D, Table 2). From initial list, in silico analysis also excluded Complement protease C1s as SCP partner (Fig. 3D, Table 2).

Distinctly from Heparin, SCP can interact with angiotensinogen ( $\Delta \mathrm{G}=-13.75 \mathrm{kcal} / \mathrm{mol}$, Table 2, Fig. 3F), Complement protease $\mathrm{C} 1 \mathrm{r}$ $(\Delta \mathrm{G}=-7.18 \mathrm{kcal} / \mathrm{mol}$, Table 2 , Fig. $3 \mathrm{G}$ ) and the complement factor $\mathrm{B}$ $(\Delta \mathrm{G}=-15.24 \mathrm{kcal} / \mathrm{mol}$, Table 2, Fig. 3E).

Table 1

MS/MS data from subsets with increased Tm after incubation with SCP.

\begin{tabular}{|c|c|c|c|c|c|c|}
\hline Fraction & ID & $\begin{array}{l}\text { Unique } \\
\text { peptides }\end{array}$ & $\begin{array}{l}\text { Spectrum } \\
\text { count }\end{array}$ & Coverage & Protein score & Description \\
\hline pl1 & sp|P00751|CFAB_HUMAN & 45 & 134 & 0.5039 & 390.4454 & Complement factor B OS $=$ Homo sapiens $\mathrm{GN}=\mathrm{CFB} \mathrm{PE}=1 \mathrm{SV}=2$ \\
\hline pl1 & sp|P02654|APOC1_HUMAN & 2 & 6 & 0.1566 & 19.9095 & Apolipoprotein C-I OS $=$ Homo sapiens $\mathrm{GN}=\mathrm{APOC} 1 \mathrm{PE}=1 \mathrm{SV}=1$ \\
\hline pl1 & sp|P51884|LUM_HUMAN & 8 & 22 & 0.2337 & 65.4736 & Lumican OS $=$ Homo sapiens $\mathrm{GN}=\mathrm{LUM} \mathrm{PE}=1 \mathrm{SV}=2$ \\
\hline pl1 & sp|P00736|C1R_HUMAN & 25 & 76 & 0.3106 & 223.2989 & Complement $\mathrm{C} 1 \mathrm{r}$ subcomponent $\mathrm{OS}=$ Homo sapiens $\mathrm{GN}=\mathrm{C} 1 \mathrm{R} \mathrm{PE}=1 \mathrm{SV}=2$ \\
\hline pl1 & sp|P01765|HV304_HUMAN & 1 & 7 & 0.3391 & 25.0881 & Ig heavy chain V-III region TIL OS $=$ Homo sapiens $\mathrm{PE}=1 \mathrm{SV}=1$ \\
\hline pl1 & sp|043866|CD5L_HUMAN & 15 & 40 & 0.5043 & 128.0102 & $\mathrm{CD} 5$ antigen-like $\mathrm{OS}=$ Homo sapiens $\mathrm{GN}=\mathrm{CD} 5 \mathrm{~L} \mathrm{PE}=1 \mathrm{SV}=1$ \\
\hline pl1 & sp|P00734|THRB_HUMAN & 14 & 50 & 0.3087 & 138.1271 & Prothrombin $\mathrm{OS}=$ Homo sapiens $\mathrm{GN}=\mathrm{F} 2 \mathrm{PE}=1 \mathrm{SV}=2$ \\
\hline pl1 & sp|Q14624|ITIH4_HUMAN & 56 & 168 & 0.5301 & 45.1547 & $\begin{array}{l}\text { Inter-alpha-trypsin inhibitor heavy chain } \mathrm{H} 4 \mathrm{OS}=\text { Homo sapiens } \mathrm{GN}=\mathrm{ITIH} 4 \mathrm{PE}=1 \\
\mathrm{SV}=4\end{array}$ \\
\hline $\mathrm{pl} 2$ & sp|P05546|HEP2_HUMAN & 25 & 84 & 0.3808 & 220.1425 & Heparin cofactor $2 \mathrm{OS}=$ Homo sapiens $\mathrm{GN}=\mathrm{SERPIND} 1 \mathrm{PE}=1 \mathrm{SV}=3$ \\
\hline $\mathrm{pl} 2$ & sp|P01610|KV118_HUMAN & 2 & 13 & 0.3704 & 41.5637 & Ig kappa chain V-I region WEA OS $=$ Homo sapiens $\mathrm{PE}=1 \mathrm{SV}=1$ \\
\hline $\mathrm{pl} 2$ & sp|P04264|K2C1_HUMAN & 8 & 12 & 0.1242 & 33.7772 & Keratin, type II cytoskeletal $1 \mathrm{OS}=$ Homo sapiens $\mathrm{GN}=\mathrm{KRT} 1 \mathrm{PE}=1 \mathrm{SV}=6$ \\
\hline $\mathrm{pl} 2$ & sp|P01764|HV303_HUMAN & 5 & 28 & 0.4274 & 92.6675 & Ig heavy chain V-III region VH26 OS $=$ Homo sapiens $\mathrm{PE}=1 \mathrm{SV}=1$ \\
\hline $\mathrm{pl} 2$ & sp|O43866|CD5L_HUMAN & 8 & 26 & 0.2651 & 75.4368 & $\mathrm{CD} 5$ antigen-like $\mathrm{OS}=$ Homo sapiens $\mathrm{GN}=\mathrm{CD} 5 \mathrm{~L} \mathrm{PE}=1 \mathrm{SV}=1$ \\
\hline $\mathrm{pl} 2$ & sp|P19827|ITIH1_HUMAN & 42 & 161 & 0.4435 & 53.5754 & $\begin{array}{l}\text { Inter-alpha-trypsin inhibitor heavy chain } \mathrm{H} 1 \mathrm{OS}=\text { Homo sapiens } \mathrm{GN}=\mathrm{ITIH} 1 \mathrm{PE}=1 \\
\mathrm{SV}=3\end{array}$ \\
\hline $\mathrm{pl} 2$ & sp|P02654|APOC1_HUMAN & 2 & 4 & 0.1566 & 11.4456 & Apolipoprotein C-I OS = Homo sapiens GN $=$ APOC1 PE $=1 \mathrm{SV}=1$ \\
\hline $\mathrm{pl} 2$ & sp|P51884|LUM_HUMAN & 9 & 26 & 0.2751 & 76.0671 & Lumican OS $=$ Homo sapiens $\mathrm{GN}=\mathrm{LUM} \mathrm{PE}=1 \mathrm{SV}=2$ \\
\hline $\mathrm{pl} 4$ & sp|P04003|C4BPA_HUMAN & 2 & 6 & 0.0687 & 2.0625 & C4b-binding protein alpha chain $\mathrm{OS}=$ Homo sapiens $\mathrm{GN}=\mathrm{C} 4 \mathrm{BPA} \mathrm{PE}=1 \mathrm{SV}=2$ \\
\hline $\mathrm{pl} 4$ & sp|P01593|KV101_HUMAN & 0 & 11 & 0.2778 & 33.9559 & Ig kappa chain V-I region AG OS $=$ Homo sapiens $\mathrm{PE}=1 \mathrm{SV}=1$ \\
\hline $\mathrm{pl} 4$ & sp|P05546|HEP2_HUMAN & 10 & 33 & 0.2365 & 8.6671 & Heparin cofactor $2 \mathrm{OS}=$ Homo sapiens $\mathrm{GN}=\mathrm{SERPIND} 1 \mathrm{PE}=1 \mathrm{SV}=3$ \\
\hline $\mathrm{pl} 4$ & sp|P00751|CFAB_HUMAN & 19 & 36 & 0.2369 & 98.0438 & Complement factor B OS $=$ Homo sapiens $\mathrm{GN}=\mathrm{CFB} \mathrm{PE}=1 \mathrm{SV}=2$ \\
\hline $\mathrm{pl} 4$ & sp|P11226|MBL2_HUMAN & 2 & 3 & 0.0685 & 5.9636 & Mannose-binding protein $\mathrm{C} \mathrm{OS}=$ Homo sapiens $\mathrm{GN}=\mathrm{MBL} 2 \mathrm{PE}=1 \mathrm{SV}=2$ \\
\hline pl5 & sp|P00739|HPTR_HUMAN & 2 & 27 & 0.2644 & 71.6814 & Haptoglobin-related protein OS = Homo sapiens $\mathrm{GN}=\mathrm{HPR} \mathrm{PE}=1 \mathrm{SV}=2$ \\
\hline pl5 & sp|P00751|CFAB_HUMAN & 25 & 52 & 0.3259 & 148.8004 & Complement factor B OS $=$ Homo sapiens GN $=$ CFB PE $=1 \mathrm{SV}=2$ \\
\hline pl5 & sp|P06309|KV205_HUMAN & 3 & 18 & 0.5043 & 52.7296 & Ig kappa chain V-II region GM607 (fragment) OS $=$ Homo sapiens $\mathrm{PE}=4 \mathrm{SV}=1$ \\
\hline pl5 & sp|P05090|APOD_HUMAN & 1 & 3 & 0.0794 & 8.5373 & Apolipoprotein D OS $=$ Homo sapiens $\mathrm{GN}=\mathrm{APOD} \mathrm{PE}=1 \mathrm{SV}=1$ \\
\hline pl5 & sp|P01764|HV303_HUMAN & 6 & 35 & 0.5897 & 122.1152 & Ig heavy chain V-III region VH26 OS $=$ Homo sapiens $\mathrm{PE}=1 \mathrm{SV}=1$ \\
\hline pl5 & sp|043866|CD5L_HUMAN & 4 & 9 & 0.196 & 30.3699 & $\mathrm{CD} 5$ antigen-like $\mathrm{OS}=$ Homo sapiens $\mathrm{GN}=\mathrm{CD} 5 \mathrm{~L} \mathrm{PE}=1 \mathrm{SV}=1$ \\
\hline pl5 & sp|P51884|LUM_HUMAN & 6 & 16 & 0.1746 & 46.7602 & Lumican OS $=$ Homo sapiens $\mathrm{GN}=\mathrm{LUM} \mathrm{PE}=1 \mathrm{SV}=2$ \\
\hline pl5 & sp|P06310|KV206_HUMAN & 3 & 18 & 0.4662 & 49.9613 & Ig kappa chain V-II region RPMI 6410 OS $=$ Homo sapiens $\mathrm{PE}=4 \mathrm{SV}=1$ \\
\hline pl5 & sp|P00450|CERU_HUMAN & 28 & 71 & 0.3239 & 237.7352 & Ceruloplasmin $\mathrm{OS}=$ Homo sapiens $\mathrm{GN}=\mathrm{CP} \mathrm{PE}=1 \mathrm{SV}=1$ \\
\hline pl5 & sp|P09871|C1S_HUMAN & 12 & 35 & 0.141 & 98.5371 & Complement $\mathrm{C} 1 \mathrm{~s}$ subcomponent $\mathrm{OS}=$ Homo sapiens $\mathrm{GN}=\mathrm{C} 1 \mathrm{~S} \mathrm{PE}=1 \mathrm{SV}=1$ \\
\hline pl5 & sp|P00736|C1R_HUMAN & 11 & 30 & 0.1631 & 88.7816 & Complement $\mathrm{C} 1 \mathrm{r}$ subcomponent $\mathrm{OS}=$ Homo sapiens $\mathrm{GN}=\mathrm{C} 1 \mathrm{R} \mathrm{PE}=1 \mathrm{SV}=2$ \\
\hline pl5 & sp|P01019|ANGT_HUMAN & 2 & 3 & 0.0577 & 7.9715 & Angiotensinogen $\mathrm{OS}=$ Homo sapiens $\mathrm{GN}=\mathrm{AGT} \mathrm{PE}=1 \mathrm{SV}=1$ \\
\hline pl5 & sp|P36955|PEDF_HUMAN & 6 & 10 & 0.1435 & 232,821 & Pigment epithelium-derived factor OS $=$ Homo sapiens $\mathrm{GN}=\mathrm{SERPINF} 1 \mathrm{PE}=1 \mathrm{SV}=4$ \\
\hline
\end{tabular}

a The list presents the proteins with concentration below $2 \mathrm{ng}$ in experiments with no fluorescence emission signal and above it when fluorescence emission detect. 
A

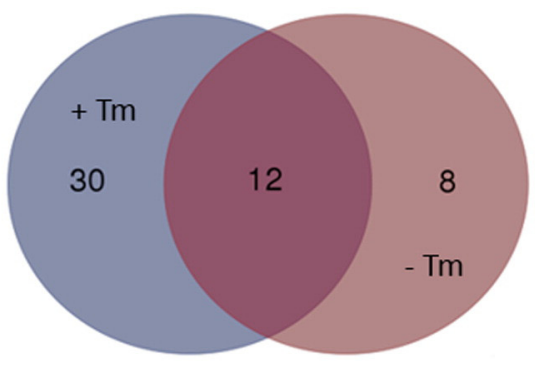

C

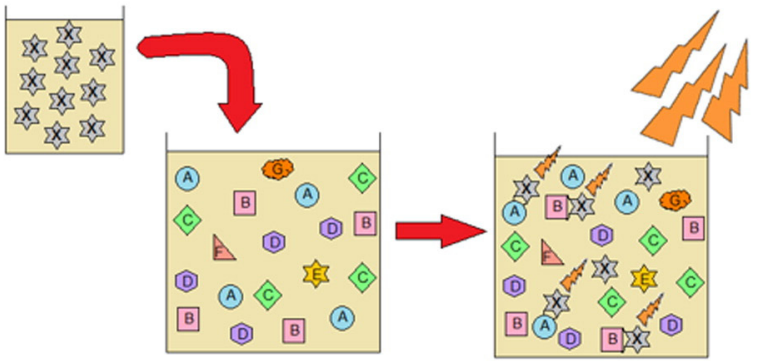

D

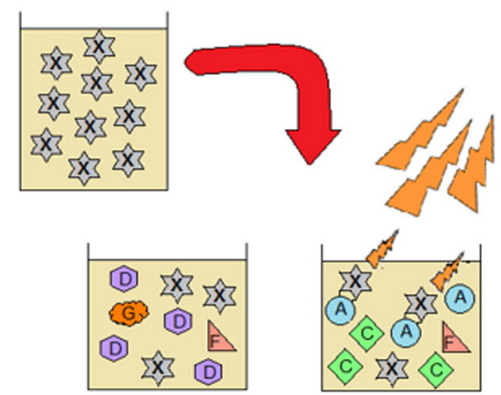

B

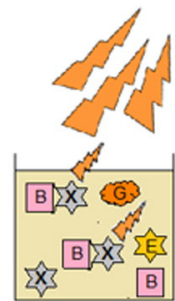

Alpha-1-antichymotrypsin

Alpha-1B-glycoprotein

Apolipoprotein A-I

Apolipoprotein A-IV

Apolipoprotein B-100

Apolipoprotein C-I

Apolipoprotein D

Apolipoprotein $\mathrm{E}$

Beta-2-glycoprotein 1

C4b-binding protein alpha chain

CD5 antigen-like

Ceruloplasmin $\mathrm{O}$

$\mathrm{C} 1 \mathrm{q}$

Complement $\mathrm{C} 1 \mathrm{r}$ subcomponent

Complement $\mathrm{C} 1$ s subcompon

Complement component $\mathrm{C} 8$ gamma chain

Complement factor $B$

Ficolin-3

Haptoglobin-related protein

Hemoglobin subunit alpha

Heparin cofactor 2

Ig heavy chain $\mathrm{V}$-I region $\mathrm{HG} 3$

Ig heavy chain $V$-III region GA

Ig kappa chain $\mathrm{V}$-I region AG

Ig kappa chain V-II region GM607 (Fragment)

Ig kappa chain $\mathrm{V}$-III region $\mathrm{HAH}$

Ig kappa chain $V$-IV region (Fragment)

Ig lambda chain $V$ region $4 A$

Ig lambda chain $V-V$ region DEL

Ig lambda-7 chain C region

Inter-alpha-trypsin inhibitor heavy chain $\mathrm{H} 1$

Inter-alpha-trypsin inhibitor heavy chain $\mathrm{H} 4$

Lumican

Mannose-binding protein $C$

Pigment epithelium-derived factor

Platelet factor 4

Prothrombin

Serum amyloid P-component

Vitamin K-dependent protein S

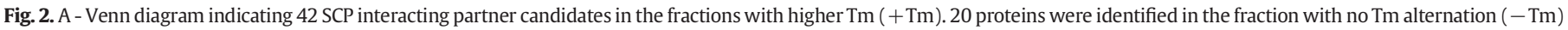

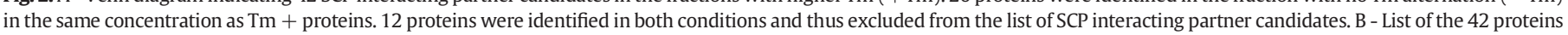

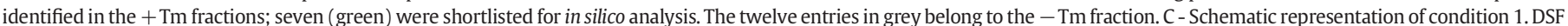

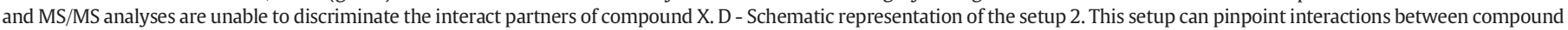
$\mathrm{X}$, proteins $\mathrm{A}$, and $\mathrm{B}$; this is because the increased Tm fraction containing $\mathrm{C}$ and $\mathrm{D}$ is only altered if $\mathrm{A}$ or $\mathrm{B}$ are present.

\section{Discussion}

\subsection{The contributions of this approach in a ligand interactome study}

Heparin is the most widely adopted drug for treatment of proclotting disorders [12,33]. However, its use has many side effects such as bleeding, thrombocytopenia, bruises, contact dermatitis, urticarial, and necrosis of epithelial tissue, to name a few [12,13,34-36]. In this regard, the search for alternative medication is indispensable. Sulfated polysaccharides have emerged as a promising substitute for Heparins $[1,4,14,17,21]$. The citrus pectin extracted from the mesocarp of the

Table 2

PEARLS estimation.

\begin{tabular}{lr}
\hline Complex & \multicolumn{1}{c}{$\Delta \mathrm{G}$} \\
\hline Angiotensinogen + SCP & $-13.75 \mathrm{kcal} / \mathrm{mol}$ \\
Heparin cofactor II + SCP & $-1.02 \mathrm{kcal} / \mathrm{mol}$ \\
Complement factor B + SCP & $-15.24 \mathrm{kcal} / \mathrm{mol}$ \\
Platelet factor IV + SCP & $-10.47 \mathrm{kcal} / \mathrm{mol}$ \\
Prothrombin I + SCP & $3.01 \mathrm{kcal} / \mathrm{mol}$ \\
Complement protease C1R & $-7.18 \mathrm{kcal} / \mathrm{mol}$ \\
Complement protease C1S + SCP & $24.59 \mathrm{kcal} / \mathrm{mol}$ \\
\hline
\end{tabular}

Citrus sinensis (SCP) has shown to be a rich source for obtaining sulfated polysaccharides with the desired anticoagulant properties [22]. Its native structure consists almost entirely of repeating units of D-GalpA (1 $\rightarrow 4$ )-linked and some traces of galactose (1.8\%), glucose (1.5\%), arabinose $(0.8 \%)$, and rhamnose $(0.4 \%)$. After sulfation, sulfate groups are linked in positions 0-2 and/or O-3 of GalpA units [22].

SCP can specifically interact in vitro with endogenous anticoagulant HCII, facilitating its interaction with thrombin, and likely interact with the HCII-Thrombin complex to strengthen the interaction [22]. Moreover, it was shown that SCP cannot inhibit thrombin in the absence of $\mathrm{HCII}$ and AT [22]. This preliminary scenario resembles the anticoagulant effect of heparin achieved by binding to HCII and AT [1-5]. Defining the interaction partners of SCP is fundamental to evaluate if its pharmacological side effects will be as harmful as those from heparin. Here, we performed an in-depth and robust profiling to search for SCP interacting partner candidates by combining several orthogonal techniques.

Removal of albumin, the most abundant protein in the plasma, is considered one of the main hurdles for the viability of this project. Its high concentration hampers the identification of interactions and presence of lesser abundant molecules in the blood because it binds with high affinity to the chromatographic columns ultimately contaminating the chromatographic fractions. Mass spectrometry based proteomics 
A

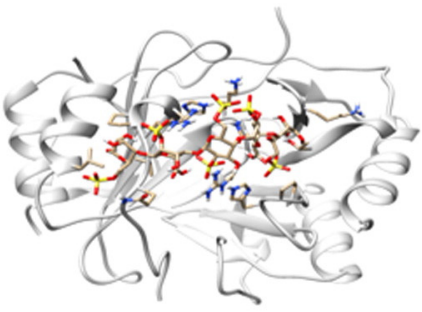

C

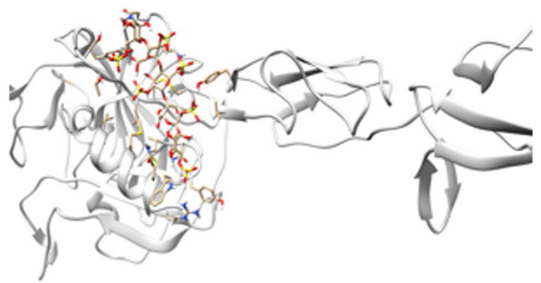

$\mathbf{E}$

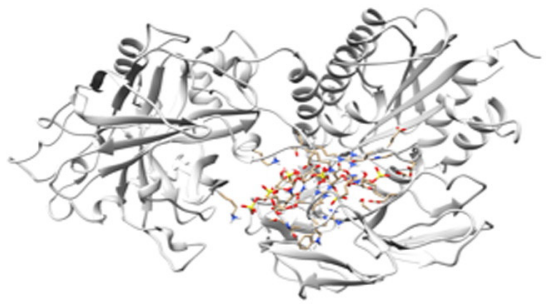

B

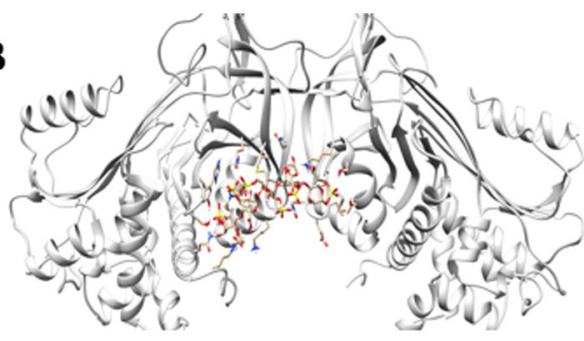

D

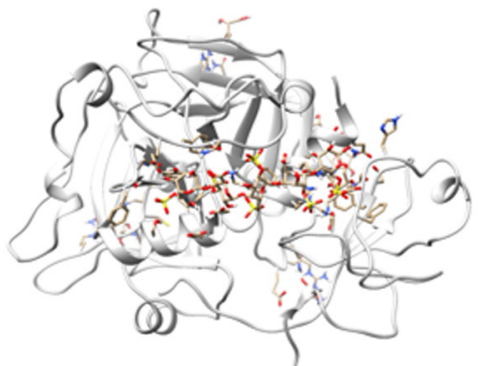

$\mathbf{F}$

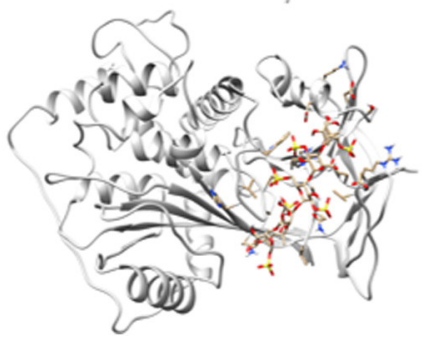

G

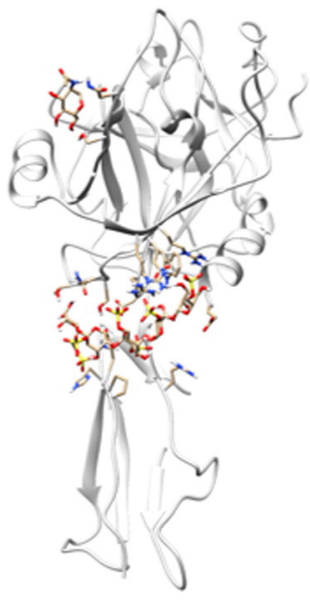

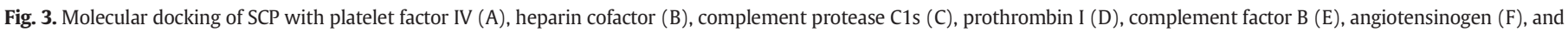
complement protease $\mathrm{C} 1 \mathrm{r}(\mathrm{G})$. Proteins are represented in grey cartoon and SCP as stick model with $\mathrm{C}$ atoms in beige, $\mathrm{O}$ atoms in red and $\mathrm{N}$ atoms in blue and $\mathrm{S}$ atoms in yellow.

also suffers from albumin's high abundancy as it suppresses the ionization of competing molecules, consequently shadowing the less abundant ones.

This limitation motivated us in establishing a simple and non-expensive protocol for albumin depletion that minimally affects the remaining plasma proteins. There are several strategies for achieving this, viz.: chromatography [37-42], ammonium sulfate precipitation [43,44], ethanol precipitation, and changes in $\mathrm{pH}$ [45] to exemplify a few. Here, we used a modified Cohn process due to its convenience and minimally affecting the remaining plasma proteins (Fig. 1A).

After albumin depletion, three distinct chromatographic steps were used for fractionating the plasma proteins. These steps are important to obtain subsets of SPC protein interacting candidates that can be further assessed by DSF and mass spectrometry (Fig. 2C-D). We now exemplify our process with a hypothetical experiment that aims in identifying the proteins (A through $G$ ) that are interacting partners of compound X. Among them, say, only proteins A and B interact with X. In setup 1 (without fractionation), proteins $A-D$ are in the same concentration and are detectable by DSF; E-G, are below the DSF detection threshold. Given the limitations, setup 1 lists proteins $a-d$ as the interacting candidates to X (Fig. 2C); further validation is necessary to certify if any of the four proteins really interacts with X. Setup 2 relies on four chromatographic fractions, each containing different subsets of proteins (subset $1,2,3$, and 4 composed of proteins $\{G, F, D\},\{A, C, F\},\{B, E, G\}$, and $\{D$, $E\}$, respectively). In this case, no interaction would be detected in samples with the absence of proteins A or B (Fig. 2D), reducing in $50 \%$ the number of candidates. This rational was extrapolated in this work by relying on plasma fractionation to narrow down on the possibilities of interacting partner candidates.

After fractionation, the search for SCP interacting partners was performed by fluorescent based thermal assay that have been extensively used for studies addressing drug discovery and for pinpointing interactions [46-57]. Proteomics showed that fractions pl1, pl2, pl4, and pl5
(Table S1) contain hundreds of proteins. In this regard, interacting partners prior to in silico molecular docking analysis, were shortlisted by excluding those based on their DSF results in different protein concentration, being absent in subsets with no Tm alternation, or on data from previous reports regarding their role in coagulation cascade.

Altogether, the repertoire of techniques we employed enabled identifying several SCP interaction partners not described for heparin; viz.: angiotensinogen, zymogen protease $\mathrm{C} 1 \mathrm{r}$, and complement factor $\mathrm{B}$. Indeed, with enough computing resources, it can be argued that SCP interactors common to those from heparin could be predicted solely with in silico analysis; yet, supporting experimental data is indispensable. Here, we introduced a hybrid strategy that combines proteomics with in silico molecular docking. Our strategy significantly reduces the number of candidates to be computationally verified thus reducing the computational burden and, most importantly, the chances for false positives.

\subsection{The physiological role of probable SCP interactions}

For experimental setups like the one introduced here, it is still imperative to follow-up on results with experiments to increase confidence on the direct interaction; some examples are surface plasmon resonance and affinity chromatography. In a previous report, [22] performed affinity assays showing a direct interaction between SCP and HCII and no direct association with thrombin [22]. These initial results served as motivation to expand the list of interaction candidates with a broader method such as the one presented. Our hybrid approach corroborated with the results from [22] Likewise, our expanded list of interacting partners provides the stepping-stones for future validation experiments.

Thrombocytopenia [58] is a common side effect to patients under treatment with heparin; such undesired effect would not be overcome by switching to SCP administration because heparin-platelet factor 4 
association would occur. The formation of this complex leads to platelet aggregation, destruction, and damage to the vascular endothelium ultimately activating the coagulation cascade and increasing thrombin synthesis [11,59]. In this regard, molecular modifications to the SCP structure are desirable to obtain new drugs with decrease platelet factor 4 association.

Some SCP targets are not described for heparin; examples are: angiotensinogen, zymogen protease $\mathrm{C} 1 \mathrm{r}$, and complement factor $\mathrm{B}$. If the SCP interaction with angiotensinogen somehow blocks or prevents its cleavage in the decapeptide angiotensin I, this interaction can then reduce blood pressure. This would be a very desirable effect in addition to the already proven anticoagulant effect. This will contribute in future treatments of hypertensive patients prone to thromboembolic disorders. The interaction between SCP with zymogen protease C1r and the complement factor B, also observed in our results, suggest a possible immunosuppressive or immunostimulatory effect. It is known that the complement system is part of the innate immune system and is responsible for major effector mechanisms of antibody-mediated immunity [60]. Thus, inhibition of C1r protease zymogen and factor B proteolytic activity may lead to a decrease in the activity of the complement system. However, taking into account that there are other ways of activating this system independent of these factors, this interaction may also not lead to unexpected biological effects.

\section{Concluding remarks}

Here, we fractionated the human plasma and identified interacting partner candidates to a chemically sulfated pectin from Citrus sinensis (SCP) that has an anticoagulant activity. The results indicate that SCP interacts directly with HCII, probably favoring its interaction with thrombin. Moreover, an interaction between SCP and AT probably requires an association with thrombin or factor Xa. These results are valuable as we demonstrate that the SCP anticoagulant activity is likely decurrent from its interaction with HCII. Moreover, we postulate that SCP may also be involved in activities related to the defense system against pathogens; this is evidenced by the potential SCP interactions with complement factors and also in processes related to the control of blood pressure evidenced by the interaction of SCP and angiotensinogen. Our results will be of great value for fueling future studies on this anticoagulant and in the design of new SCP-based molecules.

\subsection{Data availability}

All our mass spectrometry raw files, Comet search results and SEPro files are made available for download at http://proteomics.fiocruz.br/ supplementaryfiles/santana2016.

Supplementary data to this article can be found online at http://dx. doi.org/10.1016/j.jprot.2016.06.013.

\section{Conflict of interest}

The authors declare that there is no conflict of interest regarding the publication of this paper.

\section{Acknowledgements}

The authors thank CNPq and PAPES for financial support.

\section{References}

[1] A.H.P. Gracher, T.R. Cipriani, E.R. Carbonero, P.A.J. Gorin, M. Iacomini, Antithrombin and heparin cofactor II-mediated inactivation of alpha-thrombin by a synthetic, sulfated mannogalactan, Thromb. Res. 126 (2010) e180-e187, http://dx.doi.org/10. 1016/j.thromres.2010.04.008.

[2] U. Lindahl, G. Bäckström, M. Höök, L. Thunberg, L.A. Fransson, A. Linker, Structure of the antithrombin-binding site in heparin, Proc. Natl. Acad. Sci. U. S. A. 76 (1979) 3198-3202.
[3] M. Ragazzi, D.R. Ferro, B. Perly, P. Sinaÿ, M. Petitou, J. Choay, Conformation of the pentasaccharide corresponding to the binding site of heparin for antithrombin III, Carbohydr. Res. 195 (1990) 169-185.

[4] J.C. Martinichen-Herrero, E.R. Carbonero, G.L. Sassaki, P.a.J. Gorin, M. Iacomini, Anticoagulant and antithrombotic activities of a chemically sulfated galactoglucomannan obtained from the lichen Cladonia ibitipocae, Int. J. Biol. Macromol. 35 (2005) 97-102, http://dx.doi.org/10.1016/j.jbiomac.2004.12.002.

[5] P. Sie, F. Ofosu, F. Fernandez, M.R. Buchanan, M. Petitou, B. Boneu, Respective role of antithrombin III and heparin cofactor II in the in vitro anticoagulant effect of heparin and of various sulphated polysaccharides, Br. J. Haematol. 64 (1986) 707-714.

[6] H.H. Versteeg, J.W.M. Heemskerk, M. Levi, P.H. Reitsma, New fundamentals in hemostasis, Physiol. Rev. 93 (2013) 327-358, http://dx.doi.org/10.1152/physrev. 00016.2011.

[7] R.W. Colman, Are hemostasis and thrombosis two sides of the same coin? J. Exp. Med. 203 (2006) 493-495, http://dx.doi.org/10.1084/jem.20060217.

[8] V.L. Roger, A.S. Go, D.M. Lloyd-Jones, E.J. Benjamin, J.D. Berry, W.B. Borden, D.M. Bravata, S. Dai, E.S. Ford, C.S. Fox, H.J. Fullerton, C. Gillespie, S.M. Hailpern, J.A. Heit, V.J. Howard, B.M. Kissela, S.J. Kittner, D.T. Lackland, J.H. Lichtman, L.D. Lisabeth, D.M. Makuc, G.M. Marcus, A. Marelli, D.B. Matchar, C.S. Moy, D. Mozaffarian, M.E. Mussolino, G. Nichol, N.P. Paynter, E.Z. Soliman, P.D. Sorlie, N. Sotoodehnia, T.N. Turan, S.S. Virani, N.D. Wong, D. Woo, M.B. Turner, American Heart Association Statistics Committee and Stroke Statistics Subcommittee, Executive summary: heart disease and stroke statistics-2012 update: a report from the American Heart Association, Circulation 125 (2012) 188-197, http://dx.doi.org/10. 1161/CIR.0b013e3182456d46.

[9] N. Riva, M.P. Donadini, W. Ageno, Epidemiology and pathophysiology of venous thromboembolism: similarities with atherothrombosis and the role of inflammation, Thromb. Haemost. 113 (2015) 1176-1183, http://dx.doi.org/10.1160/TH1406-0563.

[10] B. Casu, A. Naggi, G. Torri, Re-visiting the structure of heparin, Carbohydr. Res. 403 (2015) 60-68, http://dx.doi.org/10.1016/j.carres.2014.06.023.

[11] J.M. Walenga, R.L. Bick, Heparin-induced thrombocytopenia, paradoxical thromboembolism, and other side effects of heparin therapy, Med. Clin. North Am. 82 (1998) 635-658

[12] J.M. Walenga, E.P. Frenkel, R.L. Bick, Heparin-induced thrombocytopenia, paradoxical thromboembolism, and other adverse effects of heparin-type therapy, Hematol. Oncol. Clin. North Am. 17 (2003) 259-282 (viii-ix).

[13] A. Perrinaud, D. Jacobi, M.-C. Machet, C. Grodet, Y. Gruel, L. Machet, Bullous hemorrhagic dermatosis occurring at sites distant from subcutaneous injections of heparin: three cases, J. Am. Acad. Dermatol. 54 (2006) S5-S7, http://dx.doi.org/10. 1016/j.jaad.2005.01.098.

[14] S. Alban, W. Jeske, D. Welzel, G. Franz, J. Fareed, Anticoagulant and antithrombotic actions of a semisynthetic beta-1,3-glucan sulfate, Thromb. Res. 78 (1995) 201-210.

[15] P.A. Mourão, M.S. Pereira, Searching for alternatives to heparin: sulfated fucans from marine invertebrates, Trends Cardiovasc. Med. 9 (1999) 225-232.

[16] A.F.D. Vasconcelos, R.F.H. Dekker, A.M. Barbosa, E.R. Carbonero, J.L.M. Silveira, B. Glauser, M.S. Pereira, M. de L. Corradi da Silva, Sulfonation and anticoagulant activity of fungal exocellular $\beta$ - $(1 \rightarrow 6)$-D-glucan (lasiodiplodan), Carbohydr. Polym. 92 (2013) 1908-1914, http://dx.doi.org/10.1016/j.carbpol.2012.10.034.

[17] F.R. Melo, M.S. Pereira, R.Q. Monteiro, D. Foguel, P.A.S. Mourão, Sulfated galactan is a catalyst of antithrombin-mediated inactivation of alpha-thrombin, Biochim. Biophys. Acta 1780 (2008) 1047-1053, http://dx.doi.org/10.1016/j.bbagen.2008. 05.006.

[18] V.H. Pomin, Review: an overview about the structure-function relationship of marine sulfated homopolysaccharides with regular chemical structures, Biopolymers 91 (2009) 601-609, http://dx.doi.org/10.1002/bip.21200.

[19] V.M. Doctor, V. Sauls, Isolation and anticoagulant properties of a new sulfated xylan: comparison with heparin and a sodium pentosan polysulfate (SP-54), Thromb. Res. 30 (1983) 573-578.

[20] M.G. Pereira, N.M.B. Benevides, M.R.S. Melo, A.P. Valente, F.R. Melo, P.A.S. Mourão, Structure and anticoagulant activity of a sulfated galactan from the red alga, Gelidium crinale. Is there a specific structural requirement for the anticoagulant action? Carbohydr. Res. 340 (2005) 2015-2023, http://dx.doi.org/10.1016/j.carres. 2005.05.018.

[21] S. Chen, Y. Hu, X. Ye, G. Li, G. Yu, C. Xue, W. Chai, Sequence determination and anticoagulant and antithrombotic activities of a novel sulfated fucan isolated from the sea cucumber Isostichopus badionotus, Biochim. Biophys. Acta 1820 (2012) 989-1000, http://dx.doi.org/10.1016/j.bbagen.2012.03.002.

[22] N.C. Maas, A.H.P. Gracher, G.L. Sassaki, P.A.J. Gorin, M. Iacomini, T.R. Cipriani, Sulfation pattern of citrus pectin and its carboxy-reduced derivatives: influence on anticoagulant and antithrombotic effects, Carbohydr. Polym. 89 (2012) 1081-1087, http://dx.doi.org/10.1016/j.carbpol.2012.03.070.

[23] T.R. Cipriani, A.H.P. Gracher, L.M. de Souza, R.J.C. Fonseca, C.L.R. Belmiro, P.A.J. Gorin, G.L. Sassaki, M. Iacomini, Influence of molecular weight of chemically sulfated citrus pectin fractions on their antithrombotic and bleeding effects, Thromb. Haemost. 101 (2009) 860-866.

[24] J.K. Eng, T.A. Jahan, M.R. Hoopmann, Comet: an open-source MS/MS sequence database search tool, Proteomics 13 (2013) 22-24, http://dx.doi.org/10.1002/pmic. 201200439.

[25] P.C. Carvalho, D.B. Lima, F.V. Leprevost, M.D.M. Santos, J.S.G. Fischer, P.F. Aquino, J.J. Moresco, J.R. Yates, V.C. Barbosa, Integrated analysis of shotgun proteomic data with PatternLab for proteomics 4.0, Nat. Protoc. 11 (2015) 102-117, http://dx.doi.org/10. 1038/nprot.2015.133.

[26] P.C. Carvalho, J.S.G. Fischer, T. Xu, D. Cociorva, T.S. Balbuena, R.H. Valente, J. Perales, J.R. Yates 3rd, V.C. Barbosa, Search engine processor: filtering and organizing peptide 
spectrum matches, Proteomics 12 (2012) 944-949, http://dx.doi.org/10.1002/pmic. 201100529.

[27] B. Zybailov, A.L. Mosley, M.E. Sardiu, M.K. Coleman, L. Florens, M.P. Washburn, Statistical analysis of membrane proteome expression changes in Saccharomyces cerevisiae, J. Proteome Res. 5 (2006) 2339-2347, http://dx.doi.org/10.1021/ pr060161n

[28] Santana AG, Carvalho PC, Zanchin NIT, Souza TACB, A Method for Purifying Native Transthyretin from Human Plasma, (n.d.) 187.

[29] A.K. Rappe, C.J. Casewit, K.S. Colwell, W.A. Goddard, W.M. Skiff, UFF, a full periodic table force field for molecular mechanics and molecular dynamics simulations, J. Am. Chem. Soc. 114 (1992) 10024-10035, http://dx.doi.org/10.1021/ja00051a040.

[30] O. Trott, A.J. Olson, AutoDock Vina: improving the speed and accuracy of docking with a new scoring function, efficient optimization, and multithreading, J. Comput. Chem. 31 (2010) 455-461, http://dx.doi.org/10.1002/jcc.21334.

[31] L.Y. Han, H.H. Lin, Z.R. Li, C.J. Zheng, Z.W. Cao, B. Xie, Y.Z. Chen, PEARLS: program for energetic analysis of receptor-ligand system, J. Chem. Inf. Model. 46 (2006) 445-450, http://dx.doi.org/10.1021/ci0502146.

[32] T.H. Steinberg, L.J. Jones, R.P. Haugland, V.L. Singer, SYPRO orange and SYPRO red protein gel stains: one-step fluorescent staining of denaturing gels for detection of nanogram levels of protein, Anal. Biochem. 239 (1996) 223-237, http://dx.doi.org/ 10.1006/abio.1996.0319.

[33] D. de Prost, Heparin fractions and analogues: a new therapeutic possibility for thrombosis, Trends Pharmacol. Sci. 7 (1986) 496-500, http://dx.doi.org/10.1016/ 0165-6147(86)90436-0.

[34] C.P. Juergens, C. Semsarian, A.C. Keech, E.M. Beller, P.J. Harris, Hemorrhagic complications of intravenous heparin use, Am. J. Cardiol. 80 (1997) 150-154.

[35] D.R.G. Junqueira, M.d.G. Carvalho, E. Perini, Heparin-induced thrombocytopenia: a review of concepts regarding a dangerous adverse drug reaction, Rev. Assoc. Médica Bras. 199259 (2013) 161-166, http://dx.doi.org/10.1016/j.ramb.2012.11.004.

[36] M. Schindewolf, E. Lindhoff-Last, R.J. Ludwig, W.-H. Boehncke, Heparin-induced skin lesions, Lancet Lond. Engl. 380 (2012) 1867-1879, http://dx.doi.org/10.1016/S01406736(12)60409-7.

[37] J.M. Curling, J. Berglöf, L.O. Lindquist, S. Eriksson, A chromatographic procedure for the purification of human plasma albumin, Vox Sang. 33 (1977) 97-107.

[38] M.J. Harvey, The application of affinity chromatography and hydrophobic chromatography to the purification of serum albumin, Methods Plasma Protein Fractionation 1980, pp. 189-200.

[39] J.H. Berglöf, S. Eriksson, J.M. Curling, Chromatographic preparation and in vitro properties of albumin from human plasma, J. Appl. Biochem. 5 (1983) 282-292.

[40] K. Tanaka, E. Sawatani, E.M. Shigueoka, G.A. Dias, H.C. Nakao, F. Arashiro, Isolation of bovine plasma albumin by liquid chromatography and its polymerization for use in immunohematology, Braz. J. Med. Biol. Res. Rev. Bras. Pesqui. Médicas E Biológicas Soc. Bras. Biofísica Al. 34 (2001) 977-983.

[41] K. Tanaka, E.M. Shigueoka, E. Sawatani, G.A. Dias, F. Arashiro, T.C. Campos, H.C. Nakao, Purification of human albumin by the combination of the method of Cohn with liquid chromatography, Braz. J. Med. Biol. Res. Rev. Bras. Pesqui. Médicas E Biológicas Soc. Bras. Biofísica Al. 31 (1998) 1383-1388.

[42] T. Burnouf, Chromatography in plasma fractionation: benefits and future trends, J. Chromatogr. B Biomed. Appl. 664 (1995) 3-15.

[43] O.O. Odunuga, A. Shazhko, Ammonium sulfate precipitation combined with liquid chromatography is sufficient for purification of bovine serum albumin that is suitable for most routine laboratory applications, Biochem. Compd. 1 (2013) 3, http:// dx.doi.org/10.7243/2052-9341-1-3.

[44] H. Svensson, Fractionation of serum with ammonium sulfate and water dialysis, studied by electrophoresis, J. Biol. Chem. (1941) 805-825.

[45] E.J. Cohn, F.R.N. Gurd, D.M. Surgenor, B.A. Barnes, R.K. Brown, G. Derouaux, J.M. Gillespie, F.W. Kahnt, W.F. Lever, C.H. Liu, D. Mittelman, R.F. Mouton, K. Schmid, E. Uroma, A system for the separation of the components of human blood: quantitative procedures for the separation of the protein components of human plasma 1a,b,c, J. Am. Chem. Soc. 72 (1950) 465-474, http://dx.doi.org/10.1021/ ja01157a122.

[46] M.W. Pantoliano, E.C. Petrella, J.D. Kwasnoski, V.S. Lobanov, J. Myslik, E. Graf, T. Carver, E. Asel, B.A. Springer, P. Lane, F.R. Salemme, High-density miniaturized thermal shift assays as a general strategy for drug discovery, J. Biomol. Screen. 6 (2001) 429-440, http://dx.doi.org/10.1089/108705701753364922.

[47] J.E. Nettleship, J. Brown, M.R. Groves, A. Geerlof, Methods for protein characterization by mass spectrometry, thermal shift (ThermoFluor) assay, and multiangle or static light scattering, Methods Mol. Biol. Clifton NJ. 426 (2008) 299-318, http:// dx.doi.org/10.1007/978-1-60327-058-8_19.

[48] F.H. Niesen, H. Berglund, M. Vedadi, The use of differential scanning fluorimetry to detect ligand interactions that promote protein stability, Nat. Protoc. 2 (2007) 2212-2221, http://dx.doi.org/10.1038/nprot.2007.321.

[49] T.W. Geders, K. Gustafson, B.C. Finzel, Use of differential scanning fluorimetry to optimize the purification and crystallization of PLP-dependent enzymes, Acta Crystallogr. Sect. F: Struct. Biol. Cryst. Commun. 68 (2012) 596-600, http://dx.doi. org $/ 10.1107 /$ S1744309112012912.

[50] M. Vedadi, F.H. Niesen, A. Allali-Hassani, O.Y. Fedorov, P.J. Finerty, G.A. Wasney, R Yeung, C. Arrowsmith, L.J. Ball, H. Berglund, R. Hui, B.D. Marsden, P. Nordlund, M. Sundstrom, J. Weigelt, A.M. Edwards, Chemical screening methods to identify ligands that promote protein stability, protein crystallization, and structure determination, Proc. Natl. Acad. Sci. U. S. A. 103 (2006) 15835-15840, http://dx.doi.org/10. 1073/pnas.0605224103.

[51] B.J. Davis, D.A. Erlanson, Learning from our mistakes: the "unknown knowns" in fragment screening, Bioorg. Med. Chem. Lett. 23 (2013) 2844-2852, http://dx.doi. org/10.1016/j.bmcl.2013.03.028

[52] A. Larsson, A. Jansson, A. Åberg, P. Nordlund, Efficiency of hit generation and structural characterization in fragment-based ligand discovery, Curr. Opin. Chem. Biol. 15 (2011) 482-488, http://dx.doi.org/10.1016/j.cbpa.2011.06.008.

[53] D.E. Scott, M.T. Ehebauer, T. Pukala, M. Marsh, T.L. Blundell, A.R. Venkitaraman, C. Abell, M. Hyvönen, Using a fragment-based approach to target protein-protein interactions, Chembiochem Eur. J. Chem. Biol. 14 (2013) 332-342, http://dx.doi.org/ 10.1002/cbic.201200521.

[54] T.A.C.B. Souza, D.M. Trindade, C.C.C. Tonoli, C.R. Santos, R.J. Ward, R.K. Arni, A.H.C. Oliveira, M.T. Murakami, Molecular adaptability of nucleoside diphosphate kinase b from trypanosomatid parasites: stability, oligomerization and structural determinants of nucleotide binding, Mol. BioSyst. 7 (2011) 2189-2195, http://dx.doi.org/10. 1039/c0mb00307g.

[55] E.C. Moraes, G.V. Meirelles, R.V. Honorato, T. de A.C.B. de Souza, E.E. de Souza, M.T Murakami, P.S.L. de Oliveira, J. Kobarg, Kinase inhibitor profile for human nek1, nek6, and nek7 and analysis of the structural basis for inhibitor specificity, Mol. Basel Switz. 20 (2015) 1176-1191, http://dx.doi.org/10.3390/molecules20011176.

[56] D. Martinez Molina, P. Nordlund, The cellular thermal shift assay: a novel biophysical assay for in situ drug target engagement and mechanistic biomarker studies Annu. Rev. Pharmacol. Toxicol. 56 (2016) 141-161, http://dx.doi.org/10.1146/ annurev-pharmtox-010715-103715.

[57] D. Martinez Molina, R. Jafari, M. Ignatushchenko, T. Seki, E.A. Larsson, C. Dan, L. Sreekumar, Y. Cao, P. Nordlund, Monitoring drug target engagement in cells and tissues using the cellular thermal shift assay, Science 341 (2013) 84-87, http://dx.doi. org/10.1126/science.1233606.

[58] J.A. Robinson, B.E. Lewis, Plasmapheresis in the management of heparin-induced thrombocytopenia, Semin. Hematol. 36 (1999) 29-32.

[59] B.H. Chong, M. Eisbacher, Pathophysiology and laboratory testing of heparin-induced thrombocytopenia, Semin. Hematol. 35 (1998) 3-8 (discussion 35-36).

[60] D.R. Mathern, P.S. Heeger, Molecules great and small: the complement system, Clin. J. Am. Soc. Nephrol. CJASN 10 (2015) 1636-1650, http://dx.doi.org/10.2215/CjN. 06230614. 